\title{
Thinking and Practice of Undergraduate Teaching Reform of East China Jiaotong University for the Development Strategy of "China made 2025"
}

\author{
Wan Diqing , Li Zhuming, Ye Shuting, Hu Yinglin
}

School of Materials Science and Engineering, East China Jiaotong University, Nanchang 330013, China

Keywords: China made 2025; undergraduate education;teaching reform

\begin{abstract}
China made 2025" development strategy requires a lot of talent support, undergraduate education is the backbone of the basic strength and talent structure of China's higher education.Based on this background, this paper takes East China Jiaotong University as an example, with "China made 2025" development strategy, the current situation of East China Jiaotong University undergraduate teaching was analyzed and puts forward some suggestions on teachin reform of undergraduate.
\end{abstract}

\section{面向“中国制造2025”发展战略的本科教学改革思考 ---以华东交通大学为例}

\author{
万迪庆 ${ }^{1 a}$, 利助民 $^{1}$, 叶舒婷 $^{1}$, 胡芗琳 ${ }^{1}$ \\ ${ }^{1}$ 华东交通大学材料学院, 南昌, 江西, 中国 \\ adivadwan@163.com
}

关键词: 中国制造2025; 本科教学; 教学改革

中文摘要：“中国制造2025”发展战略需要大量的人才支持，本科生又是我国高校教育的基 础力量和人才结构的中坚力量。基于该背景, 本文以华东交通大学为例, 契合中国制造2025 发展战略, 对华东交通大学本科教学现状进行详细分析以及提出了若干条本科教学改革建议。

\section{1. 引言}

在制造行业方面, 自改革开放以来我国取得了空前的成功。我国制造行业通过几十年的发 展其规模已经变得十分庞大, 在该方面已然走在了世界前列。但整体技术水平不高;信息化水 平, 工业化水平及智能化水平的基础十分薄弱。在上述前提下, 国务院于2015年5月8日正式发 布了“中国制造2025”战略计划。强有力的人才支持是中国制造2025发展战略的顺利实施的首 要前提, 而本科教育是该人才动力的保障。华东交通大学是一所以轨道交通为特色的教学研究 型高校, 这些年在本科教育方面取得了较大的成功, 招生规模日益扩大。虽然我校本科生就业 水平常年在全国 50 强之列, 但在本科人才培养方面也存在些不足, 如学生实践能力欠缺, 在专 业方面不能很好的进行创新等。基于此考虑, 我们将结合中国制造2025计划, 以发展的眼光综 合分析华东交通大学本科生教学改革并提出相关的建议。

\section{2. 华东交通大学本科生教学存在的一些问题}

近些年来, 随着我国高等教育事业的迅速发展, 在本科教育方面, 华东交通大学在这些年 取得了较大的成功, 本科生人数已从 2001 年的 0.5 万人增加至 2015 年的 1.2 万人。然而, 招生规 
模的扩大也难免会带来生源质量的下降、教学资源紧张和教学质量下降等方面的难题。纵观 华东交通大学本科教育情况, 可以发现存在以下几个突出问题。

\section{1) 学校教学资源短缺问题}

大学招生规模的扩大使大学生人均教学资源拥有量下降。当前高等教育领域中, 优质教育资源 严重短缺与招生规模扩大之间的矛盾日益尖锐, 并引发了培养质量、教育公平、学生就业等一 系列教育领域高度关注的热点和难点问题。学校教学资源短缺问题在华东交通大学校内实训 以及实验教学方面反映最为突出。本来校内实训以及实验是大学生锻炼自己动手能力的好机 会, 学生在独立完成实训项目的锻炼下综合能力方面得到提高。可是, 教学资源短缺往往导致 在实践教学过程中几位学生共用一台仪器, 学生动手的机会得不到保障, 甚至催生了学生的懒 惰心理.

\section{2 )课堂教学模式单一, 缺乏互动}

由于本科生人数较多, 目前高校中常采用的一种教学模式是:几十位甚至上百位学生在一个偌 大的多媒体教室中, 老师以PPT的形式传经布道; 亦或是以黑板板书的形式进行教课。这两种教 学模式都具有明显的“后喻文化”特征, 属于“师授生听”的教学模式 ${ }^{[1]}$ 。然而老师通过上述的方 式将课本知识灌输给学生, 学生被迫被动式学习, 很容易形成填鸭式教学。长期以来, 学生会形 成厌倦心理, 没有兴趣再进行课程的学习。同时“师授生听”的教学模式缺乏老师和学生之间的 互动, 使得学生常扮演倾听者的角色, 课堂学术氛围不浓。苏格拉底那种辩论式教学方法迸发 出来的思想火花已经不复存在, 学生发现并解决问题能力以及自主创新能力得不到锻炼, 这极 大程度上制约了学生的全面发展, 与可持续性发展”中国制造2025”战略相驳。

\section{3 )考试模式陈旧}

平时成绩与考试成绩按比例分配成为最终考核成绩了大多数高校采用的考试模式。表面上 这种考试模式摒弃了传统教育的观点, 实则不然。这种考试模式缺乏一定的弹性, 为了好的 成绩，学生不得不以啃书本为主，制约了学生其他方面的发展。

\section{4) 学校教育与企业实际脱轨}

华东交通大学很多专业偏理论教学, 而在企业实践操作或模拟教学方面存在明显不足。 本科毕业生虽然具有扎实的基础知识, 但在实际操作, 解决实际生产问题能力方面存在明显 不足，导致很多刚毕业的大学生来到企业实习期间会有明显的 “水土不服”，不能很好的进 行企业的业务创新。

\section{3. 华东交通大学本科教学改革若干建议}

华东交通大学具有鲜明的专业特色, 以下从 “中国制造 2025 ” 发展战略的角度考虑, 为 华东交通大学本科教学改革提出若干建议。

\section{1) 教学资源短缺下的MOOC教学的应用和推广}

随着信息技术的普及, 基于互联网环境的教学模式日益得到广泛应用。基于广大学习者的 需要, “大型开放式网络课程” (即massive open online courses, 简称为MOOC, 慕课) 应运而生。 华东交通大学近两年以数字化教学资源和网络教学平台建设为基础, 推动课程改革, 积极开展 慕课的建设、培育工作, 取得一定成效。2014年, 华东交通大学投入 30 万建设5门慕课, 引入校 外 $8 门$ 通识教育类慕课。华东交大负责的《工程图学》SPOC课程在教育部”爱课程网”成功上线。 2015年, 该校立项建设5门慕课, 已引入校外 $15 门$ 门通识教育类慕课。MOOC的是一个新的、基于网 络的学习环境, 可以作为一个有效的教学补充, 特别适用于高校里的短期培训或特定知识培训, 可以在一定程度上解决高校的教学资源短缺问题。

\section{2)改变指导思想加强课堂学术氛围}

"中国制造2025"发展内容要求通过信息化和工业化的深度融合来引领制造行业的发展; 因此, 课堂教学的内容有必要得到相应扩容和改革。一方面老师应当及时更新知识, 应当将理 论知识与学术前沿知识, 个人研究成果结合起来讲解。通过这种结合方式的讲解可以加深学生 对理论知识的印象同时可以提高学生运用知识去发现现实问题, 解决现实问题的能力, 激发同 学们追寻未知世界的兴趣; 另一方面, 加强老师与学生之间的互动。要做到这一点, 首先要求老 
师从传统的教学模式中转变过来。在传统的“师授生听”的传统教学模式中, 实质上反映了老师 权威的位置。学生往往觉得老师传授的都是对的, 根本不会去质疑并反驳老师的说法, 渐渐的 形成了逆来顺受的心理。这种恶性循环制约了老师和学生水平的共同提高。老师应当以摆渡 人的姿态去用自己的知识去引导学生向更高层次的学问发起冲击。如此以来, 我国的教育事业 是以螺旋上升的状态运转的, 这为“中国制造2025战略”提供了源源不断的人才动力。另外, 为 了学生能够更好的从学校到企业的接轨, 要求老师以行业为主导方向, 多去企业挂职, 把握市 场需求, 从而在上课内容方面可以做到有的放矢, 自然会适当调节课时计划, 课程内容, 以便贴 近生产实际。

\section{3）吸收本科生进入项目研究}

当代我国本科生教育属于”毛坏式”加工, 以通识教育为主 ${ }^{[2]}$ 。大多数本科生在校期间通常 只能和一些基础知识打交道, 很少能接触到专业前沿技术的研究。专业前沿技术的研究大多数 是研究生完成, 这种做法其实导致一批优秀的本科生无法得到锻炼的机会。一般高校中的项目 主要由两种组成: 横向项目和纵向项目 ${ }^{[3]}$ 。纵向项目一般指的是有国家支持的基础研究型科技 项目; 横向项目一般是企业和学校老师共同完成的项目, 具有很强的实际意义。因此无论横向 项目和纵向项目都是反应了专业中的前沿科学技术。本科生加入到这些项目中来具有空前的 意义。如果本科生通过这些科研项目的锻炼, 培养了学生的科研兴趣, 可以为我国科研事业发 展挖掘一批新鲜血液。华东交通大学各院在这指导思想下, 由老师带头成立了许多工作室如理 学院的"腾杰工作室”等。这些工作室的主要成员由本科生组成。项目一般来自于导师手头的 课题, 学生在工作室中接受项目的挑战, 锻炼了专业技能, 拓展了视野。在此基础和资源下, 学 生本身也可以提出自己的想法并将其付诸于现实。在这种氛围中, 华东交通大学两位学子当选 “中国自强之星”, 每人各拥有专利数项。同时在这些项目中, 本科生加深了对专业的理解。很 大程度上避免了学生临到毕业之际仍然不知道专业用途的事件发生。通过上述描述, 可以发现 吸收本科生进入项目研究对于老师和学生是一个双赢的做法。然而华东交通大学受限于自身 条件, 项目不多及学生创新气氛不浓。虽然在吸收本科生进入项目研究方面取得了可观的成绩, 但仍然需要继续加强这方面的建设, 同时有必要建立相关管理及奖励制度。

\section{4 ) 考核模式应当多样化，专业设置应该顺应潮流}

在当今社会中需要各种各样的人才, 高校的考核模式不能一再的墨守成规, 仅以考试成绩 论英雄。考试成绩是能力体现的一方面, 但在高校教育中我们应该更多的关注学生创新能力, 独立思考问题能力的培养 ${ }^{[4-5]}$ 。高校中时常发现“高分低能”学生的身影, 一味的追求分数, 会使 得学生陷入学习误区, 不能真正的去领悟课程知识, 仅仅是会做题罢了。高校的考核模式应当 多样化, 全面化; 中国制造2025的主要内容非常强调创新和实践能力, 这要求我们不能再以考 试分数论英雄。要鼓励学校积极参加、承办各类赛事, 丰富大学生科技创新活动。华东交通大 学这几年加大对参加数学建模比赛, 挑战杯的鼓励力度。大量的学生参加各种赛事, 营造出校 园良好的学习和学术环境, 同时对学生本身也是一种历练。当然学校也应加大各类赛事活动的 开展力度, 既有利于丰富学生课外生活, 也让学生在比赛的过程中提高了抗压及创新能力。

\section{5) 深化校企合作水平}

中国制造2025发展战略迫使我们重视校企合作，该教育模式的重点在于培养学生的综合 素质和能力; 主要利用学校, 企业, 科研单位等众多的教育资源, 发挥各自在培养人才方面 的优势和特点; 把以理论知识传授为主的学校和直接培养学生实践能力, 获取工程知识的企 业, 科研单位有机的结合在一起, 真正的做到产学研相结合, 为培育出理论知识扎实, 实践 能力强的高材生提供了先决条件。华东交通大学是一所以轨道交通为特色的教学研究型大学。 近年来, 华东交通大学在以轨道交通为主轴下, 发展了先进轨道交通装备, 先进轨道交通材 料等一系列服务于轨道交通的专业方向, 同时加大了和中国中车, 北京铁道科学研究院, 各 铁路局的合作力度, 这为华东交通大学成为一所实力雄厚的大学奠定了基础。在开展校企合 作时应当警惕仅仅进行 “表面工程”。为了提升学校或企业的知名度，一些高校和企业只是 达成表面上的意向合同, 并无深入交流。同时企业和学校的本质目的不同, 企业是以盈利为 
目的的单位，而学校则是以育人为目的的单位。这会导致实习生进入企业后往往会处于被放 养的状态，无人对其进行有效的指导。学生反而会因其失去宝贵的学习时间。最后一点，校 企合作也应当注意安全管理工作的实施; 近年来, 实习过程中的学生事故频频发生, 这为学 校和企业敲响了安全警钟。

\section{结束语}

中国制造2025计划能否顺利的实施，很大一部分因素将取决于我国人才水平，而本科生 是我国人才的基础力量。如果本科生教育现状中的难题如果不解决会将会极大地阻碍中国 2025发展战略的成功实施。华东交通大学在本科教学中应该注意加强课堂学术氛围, 改变上 课指导思想、吸收本科生进入项目研究, 加大校企合作力度、改革考试模式, 并使专业设置 应该顺应潮流、同时要多承办各类赛事, 鼓励学生参加, 这样我们才能更加紧贴实际, 顺应 中国制造2025发展战略要求。

\section{致谢}

本文研究获得江西省教育厅科技项目（GJJ150536）的资助。

\section{References}

[1]Hao Mingjun, To explore theory and practice of graduate teaching mode reform ,Journal of chongqing normal university (philosophy and social sciences edition), vol.3,pp 116-118,2009.

[2]Deng Jian, Gao Min, the research of university-enterprise cooperation mode of cultivating the ability of innovative, China power education.vol.129, pp.26-27,2009.

[3]Ba Shuyin,Undergraduate teaching and the trend of research in American researched university,Modern education science. vol.179,pp:108-110,2014.

[4] Shaocong Lai, Hua Hong, ZhenLiang Wang, the research-oriented teaching reform and innovative talent training, China university teaching. vol8,pp:12-14,2007.

[5] Xinnan Fan, Huang Bo, ChangPing Zhu, the mode of graduate students in the undergraduate innovative practice ability training, the application of experimental technology and management,vol22, pp: 89-92,2005. 